\title{
Schiff Base liquid Crystals with Terminal Alkoxy Group Synthesis and Thermotropic Properties
}

\author{
Nasreen R. Jber *, Mohammad M. Shukur and Ahmed A. Najaf \\ Department of Chemistry, College of Science, Al-Nahrain University, Baghdad-Iraq. \\ *E-mail: nasreen301174@yahoo.com.
}

\begin{abstract}
A new homologous series of Schiff base esters comprising a terminal alkoxy substituent $\mathrm{N}-\{(\mathrm{n}-$ alkoxy-4"-bezoyloxy)-4`- benzylidene\}-4-butyl aniline was studied. The alkyloxy substituent contributes to the molecular polarizability, thus, affecting intermolecular interactions, hence, resulting in nematic polymorphism. The mesomorphic properties were studied using polarizing optical microscope (POM). The lower members, n-methoxy and n-ethoxy derivatives were nonmesogens, enantiotropic nematogenic phase was observed on further lengthening of the alkyl chain from $\mathrm{C} 3$ to $\mathrm{C} 6$ and smectogenic phase was observed for compounds $\mathrm{C} 7$ and C8. FT-IR, ${ }^{1} \mathrm{HNMR}$, ${ }^{13} \mathrm{CNMR}$, EI-MS and elemental analysis were employed to elucidate the molecular structure of the title compounds whereas the liquid crystal properties were determined by POM analysis. The mesomorphic behaviors of the homologous compounds are rationalized based on the varying lengths of the alky chain.
\end{abstract}

Keywords: Schiff s bases, nematic liquid crystals.

\section{Introduction}

Liquid crystalline materials have many practical applications in scientific and technological areas, in particular as display devices, organic light emitting diodes, anisotropic networks, photoconductors and semiconductor materials [1-3]. High demand of new liquid crystals for applications has led to the preparation and study of numerous mesogens in particular, thermotropic liquid crystals [4-5]. Most thermotropic liquid crystals are rod-like molecules having a rigid core possessed of two or more phenyl rings and one or more flexible terminal alkyl chains. Schiff base, also known as imine $(\mathrm{CH}=\mathrm{N})$, is a linking group used in connecting the rigid core groups. Though it provides a stepped core structure, yet it retains molecular linearity, hence providing higher stability and enabling formation of mesophase [6]. Comprehensive studies on Schiff base core systems have been conducted since the discovery of $\mathrm{N}-(4-$ Methoxybenzylidene)-4-butylaniline (MBBA) which exhibited a nematic phase at room temperature [7]. Several studies have been conducted on Schiff base esters owing to their interesting properties and substantial temperature range [8-11]. Understanding of structure-property relationship is elemental on molecular modifications for synthesis of new mesogens with desirable properties and future applications [12]. Typical terminal moieties exhibiting liquid crystal properties are those alkoxy group. Polar substituents possessing strong dipole moments, thus having the ability to promote mesomorphic properties [13]. The increased dipole moment enhances the stability of the lattice and melting temperatures[14]. As the length of the terminal substituent increases, the molecules tend to orientate in a parallel arrangement [15].

\section{Instrumental}

All chemicals and solvents were of analar grade and were used without further puriffcation. Electron ionization mass spectrum (EI-MS) was recorded using a Shimadzu GCMS-QP2010 Ultra/SE mass spectrometer operating at $70 \mathrm{eV}$ ionizing energy. Samples were introduced using a direct inlet system with a source temperature of $200^{\circ} \mathrm{C}$. Microanalyses were carried out on Euro EA Elemental analyzer A-3000. FT-IR data were acquired with a 8300 Shimadzu Fourier Transform Infrared spectrophotometer in the frequency range of 4000 to $400 \mathrm{~cm}^{-1}$ with samples embedded in $\mathrm{KBr}$ pellets. ${ }^{1} \mathrm{HNMR}$ and ${ }^{13} \mathrm{CNMR}$ spectra were recorded in DMSO using a Bruker $300 \mathrm{MHz}$ NMR 
Spectrometer with Trimethylsilane (TMS) as the internal standard.

Liquid crystalline properties were investigated by POM using a (Meiji MT9000) Polarizing Optical Microscope attached to an INSTEC Hot stage. The texture of the compounds were observed using polarized light with crossed polarizers, the sample being prepared as a thin film sandwiched between a glass slide and a cover. A camera (Lumenera) was installed on the polarizing microscope.

\section{Synthesis}

The intermediate and title compounds were prepared according to the following scheme:

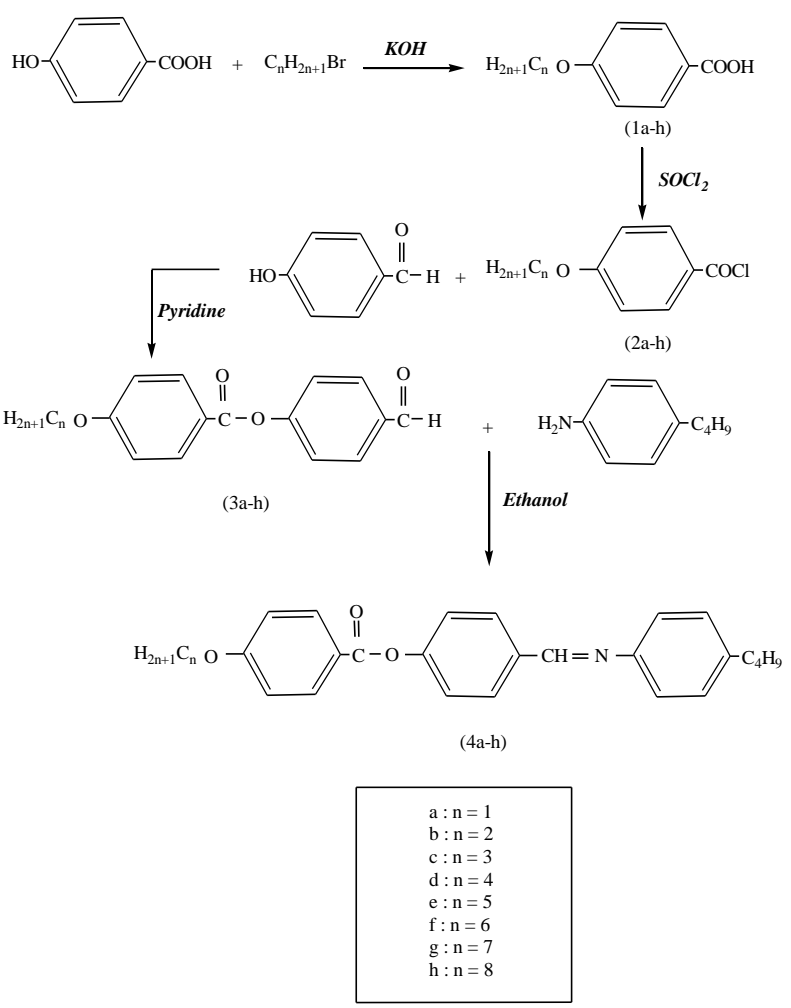

\section{Scheme (1) The synthetic pathway for the titled compounds.}

Synthesis of 4-n-alkoxybezoic acid and 4-nalkoxybezoyl chloride:

Were prepared according to previously reported methods [16].

\section{Synthesis of 4-(4-n-alkoxybezoyloxy) benzaldehyde [16]}

Equal amounts of 4-hydroxybenzaldehyde and 4-n-alkoxybezoylchoride, along with $10 \mathrm{ml}$ of dry pyridine were stirred for three hours in an ice bath. The mixture was poured into cold water acidified with $\mathrm{HCl}$ and filtered. The product was washed with cold water.

\section{Synthesis of N-\{(n-alkoxy-4“-bezoyloxy)-4` benzylidene\}-4-butyl aniline [16]:}

Equal amounts of 4-[4`-nalkoxybezoyloxy] benzaldehyde and 4-nbutylaniline, along with $30 \mathrm{ml}$ of absolute ethanol were refluxed for three hours. The mixture was cooled to room temperature and filtered. The yellow product was recrystallized with ethanol until its transition temperature remained constant (Scheme (1)). The percentage yield and analytical data of the title compounds are tabulated in Table (1). EI-MS, IR, ${ }^{1} \mathrm{HNMR}$ and ${ }^{13} \mathrm{CNMR}$ data of the representative compound $4 \mathrm{~d}$ are given as follows: EI-MS (m/z, relative intensity): 429 (20) $\left[\mathrm{M}+, 57\right.$ (100); IR (KBr) $\left(\mathrm{cm}^{-1}\right)$ : 2927.3, 2845.1 (v $\mathrm{C}-\mathrm{H}$ aliphatic); 1752.7 (v $\mathrm{C}=\mathrm{O}$ ester); 1621.4 (v $\mathrm{CH}=\mathrm{N}), 1284.3$ (v $\mathrm{C}-\mathrm{O})$, 831.2 ( $\gamma$ disubstituted benzene); ${ }^{1} \mathrm{HNMR}: \delta$ 0.94 (t, 6H (H1 \& H8)), 2.5 (t, H4), 1.57-1.75 (q, 8H, H3 \& H6), 3.94 (H5, t, 2H, - $\left.\mathrm{CH}_{2}-\mathrm{O}-\right)$, $6.98-7.42$ (dd, 4H, Ar-H), $7.94-8.19$ (dd, $4 \mathrm{H}, \mathrm{Ar}-\mathrm{H}), 8.66\left(\mathrm{~s}, 1 \mathrm{H},-\mathrm{CH}^{\mathrm{e}}=\mathrm{N}-\right) ;{ }^{13} \mathrm{CNMR}$ (100 MHz, DMSO,): $\delta 13.7-40.8$ for $\left(\mathrm{CH}_{3^{-}}\right)$ and $\left(-\mathrm{CH}_{2}-\right), 63.6\left(-\mathrm{CH}_{2} \mathrm{O}-\right), 113.9-163.1$ for aromatic carbons, $163.64(-\mathrm{CH}=\mathrm{N}-), 191.9$ (-COO-).

\section{Results and Discussion \\ Synthesis and spectral studies}

Structure elucidation of compounds $4 \mathrm{a}-\mathrm{h}$ was ascertained by using elemental analysis, mass spectrometry and IR and spectroscopic methods Figs. (1 to 4). The experimental and theoretical values obtained from the elemental analysis of 4a-h (Table (1)) were in good agreement. 
Table (1)

Percentage yields and analytical data of compound $4 a-h$.

\begin{tabular}{|c|c|c|c|c|c|}
\hline \multirow{2}{*}{ Compound } & \multirow{2}{*}{ Yield (\%) } & \multirow{2}{*}{ Formula } & \multicolumn{3}{|c|}{$\%$ Found (\% Calcd.) } \\
\hline & & & $C$ & $\begin{array}{l}H \\
\end{array}$ & $N$ \\
\hline $3 a$ & 84.5 & $\mathrm{C}_{15} \mathrm{H}_{12} \mathrm{O}_{4}$ & $70.42(70.31)$ & $4.51(4.68)$ & - \\
\hline $3 d$ & 88.3 & $\mathrm{C}_{18} \mathrm{H}_{18} \mathrm{O}_{4}$ & $72.53(72.48)$ & $5.99(6.04)$ & 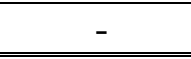 \\
\hline $3 h$ & 80.2 & $\mathrm{C}_{22} \mathrm{H}_{26} \mathrm{O}_{4}$ & $74.43(74.57)$ & $7.28(7.34)$ & - \\
\hline $4 a$ & 67.9 & $\mathrm{C}_{25} \mathrm{H}_{25} \mathrm{O}_{3} \mathrm{~N}$ & $77.58(77.51)$ & $6.34(6.45)$ & $3.58(3.61)$ \\
\hline $4 b$ & 78.6 & $\mathrm{C}_{26} \mathrm{H}_{27} \mathrm{O}_{3} \mathrm{~N}$ & 777.89(77.80) & $6.69(6.73)$ & $3.45(3.49)$ \\
\hline $4 c$ & 77.0 & $\mathrm{C}_{27} \mathrm{H}_{29} \mathrm{O}_{3} \mathrm{~N}$ & $78.11(78.07)$ & $6.88(6.98)$ & $3.32(3.37)$ \\
\hline $4 d$ & 75.3 & $\mathrm{C}_{28} \mathrm{H}_{31} \mathrm{O}_{3} \mathrm{~N}$ & 78.41(78.32) & $7.17(7.22)$ & $3.29(3.26)$ \\
\hline $4 e$ & 76.9 & $\mathrm{C}_{29} \mathrm{H}_{33} \mathrm{O}_{3} \mathrm{~N}$ & $78.64(78.55)$ & $7.39(7.44)$ & $3.10(3.16)$ \\
\hline
\end{tabular}

The molecular ion peak at $\mathrm{m} / \mathrm{z}=429$ in the mass spectrum of the representative compound $4 \mathrm{~d}$ (Fig. (1)) suggested that $4 \mathrm{~d}$ with a molecular formula of $\left(\mathrm{C}_{28} \mathrm{H}_{31} \mathrm{NO}_{3}\right)$ was successfully synthesized, the other peaks are shown in the fragmentation pattern (Scheme (2)). Fourier transform infrared (FTIR) spectrum (Fig. (2)) show that the diagnostic bands assignable to the stretching of representative compound $4 \mathrm{~d}$ were observed at the respective frequencies 2927.3, 2845.1 and $1752.7 \mathrm{~cm}^{-1}$. The absorption band assignable to the stretching of $\mathrm{CH}=\mathrm{N}$ bond was observed at frequency of $1621.4 \mathrm{~cm}^{-1}$, and these values conform with those reported in the Infrared (IR) spectra for various substituted aromatic Schiff bases[17]. The ${ }^{1}$ HNMR spectrum of $4 d$ (Fig. (3)) further supported its structure. The two triplets at $\delta=0.94 \mathrm{ppm}$ and $\delta=3.94 \mathrm{ppm}$, were, respectively ascribed to the methyl and methylene protons $\left(-\mathrm{CH}_{2} \mathrm{O}-\mathrm{Ar}\right)$, while the multiplet at $\delta=1.57 \mathrm{ppm}$ was assigned to the methylene protons of the long alkyl chain $\left\{\mathrm{CH}_{3}\left(\mathrm{CH}_{2}\right)_{2}\right\}$. The four distinct doublets between $\delta=6.98-7.90 \mathrm{ppm}$ were indicative of the aromatic $\mathrm{C}-\mathrm{H}$ and carbonyl $(\mathrm{C}=\mathrm{O}$ of ester) of protons. The singlet observed at the most downfield region, $\delta=8.66 \mathrm{ppm}$, supported the presence of the imine linking group [11]. The molecular structure of $4 \mathrm{~d}$ was further verified by using ${ }^{13}$ CNMR spectroscopy (Fig. (4)). The peak at $\delta=13.5 \mathrm{ppm}$ was attributed to the methyl carbon while the peaks between $\delta=18.8-31.1 \mathrm{ppm}$ represented the methylene carbons of the long alkyl chain. The 18 carbons of the aromatic ring in $4 \mathrm{~d}$ resonated between $\delta=113.9$ to $163.1 \mathrm{ppm}$. The peak at $\delta=163.6 \mathrm{ppm}$ and $\delta=191.9 \mathrm{ppm}$ confirmed the presence of the azomethine carbon and the carbonyl group in the molecule. 


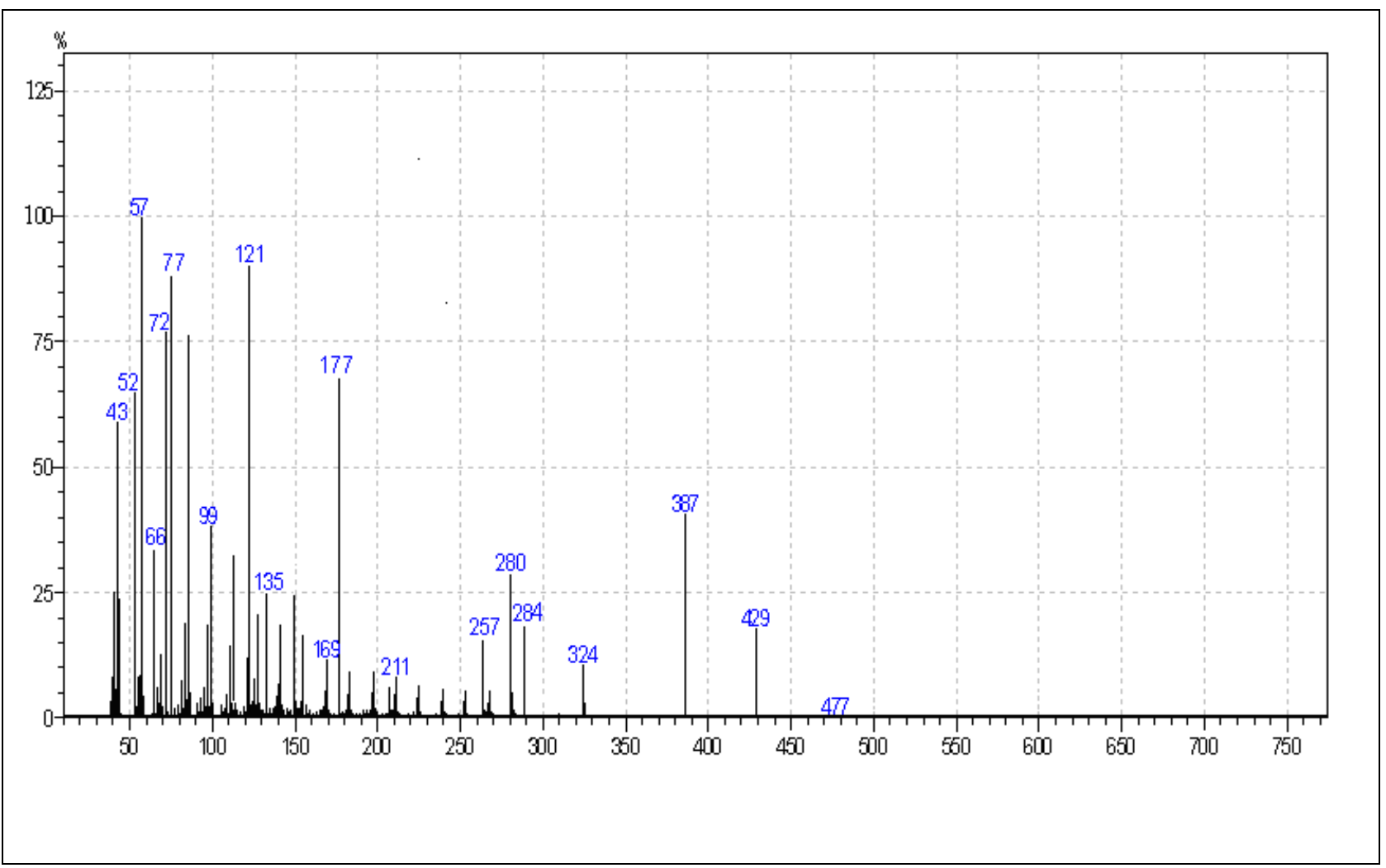

Fig.(1) EI-MS Spectrum of compound 4d.

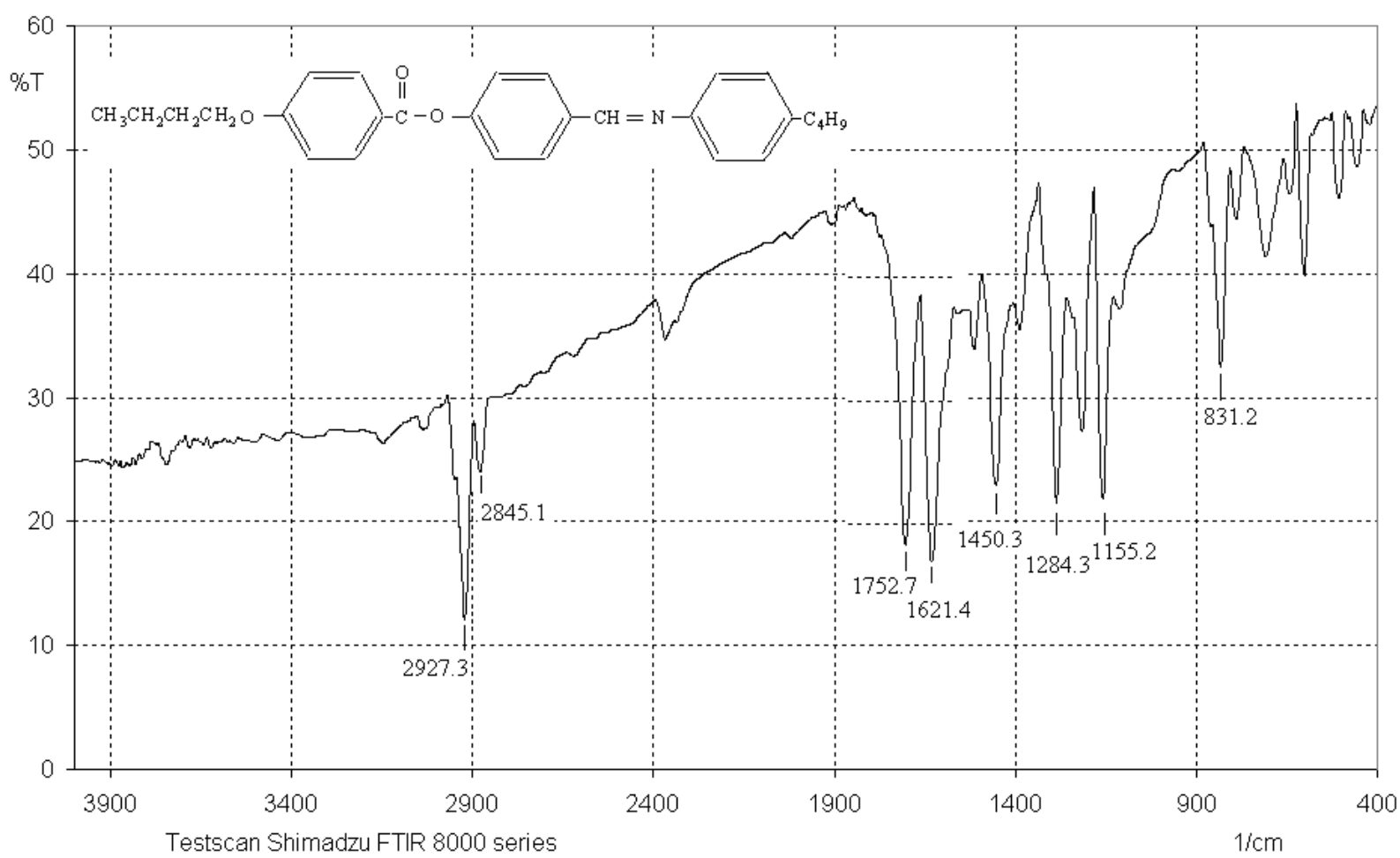

Fig.(2) FTIR spectrum of compound 4d. 


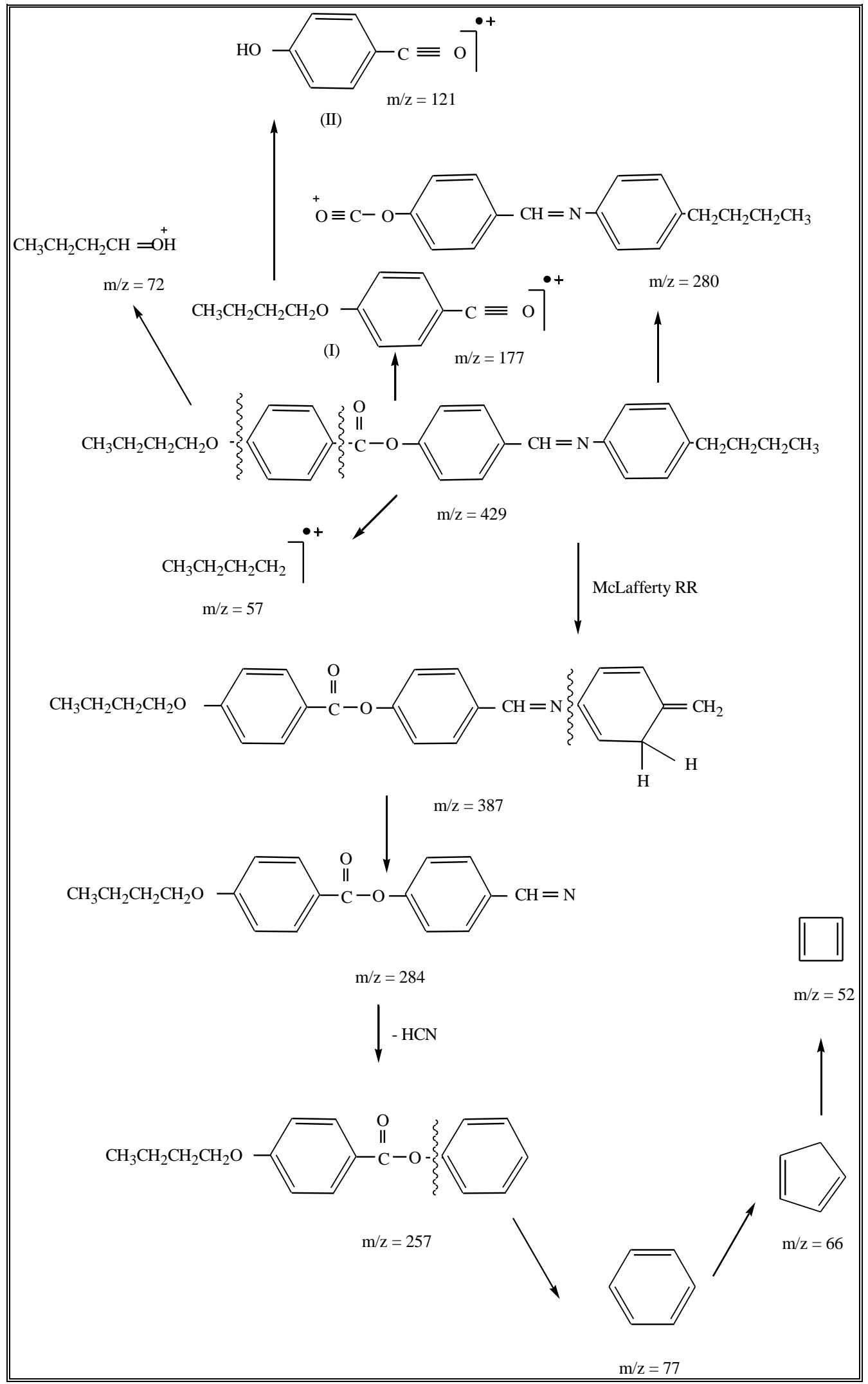

Scheme (2) The fragmentation modes for compound $4 d$. 


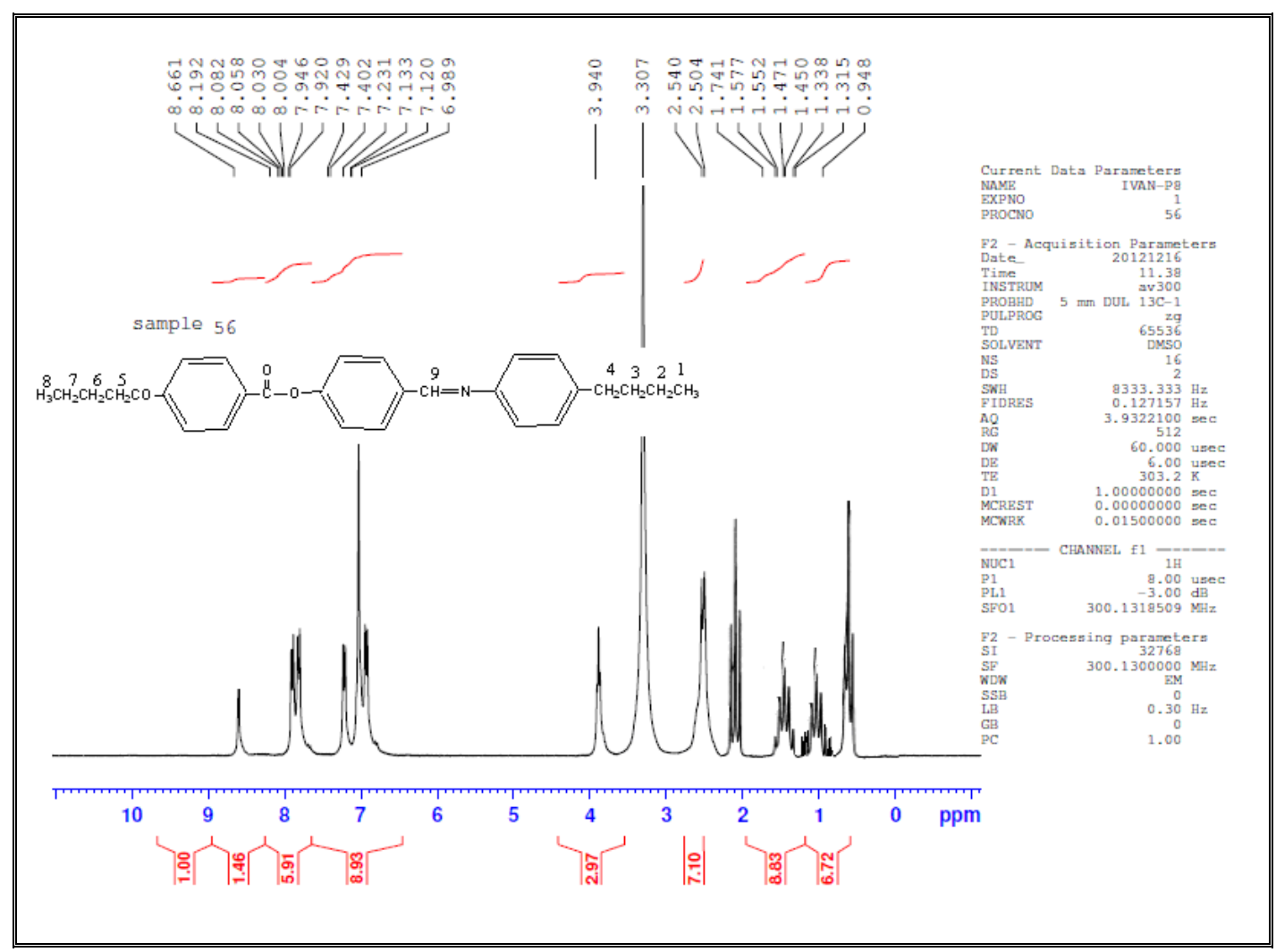

Fig.(3) ${ }^{1} \mathrm{HNMR}$ spectrum for compound $4 d$.

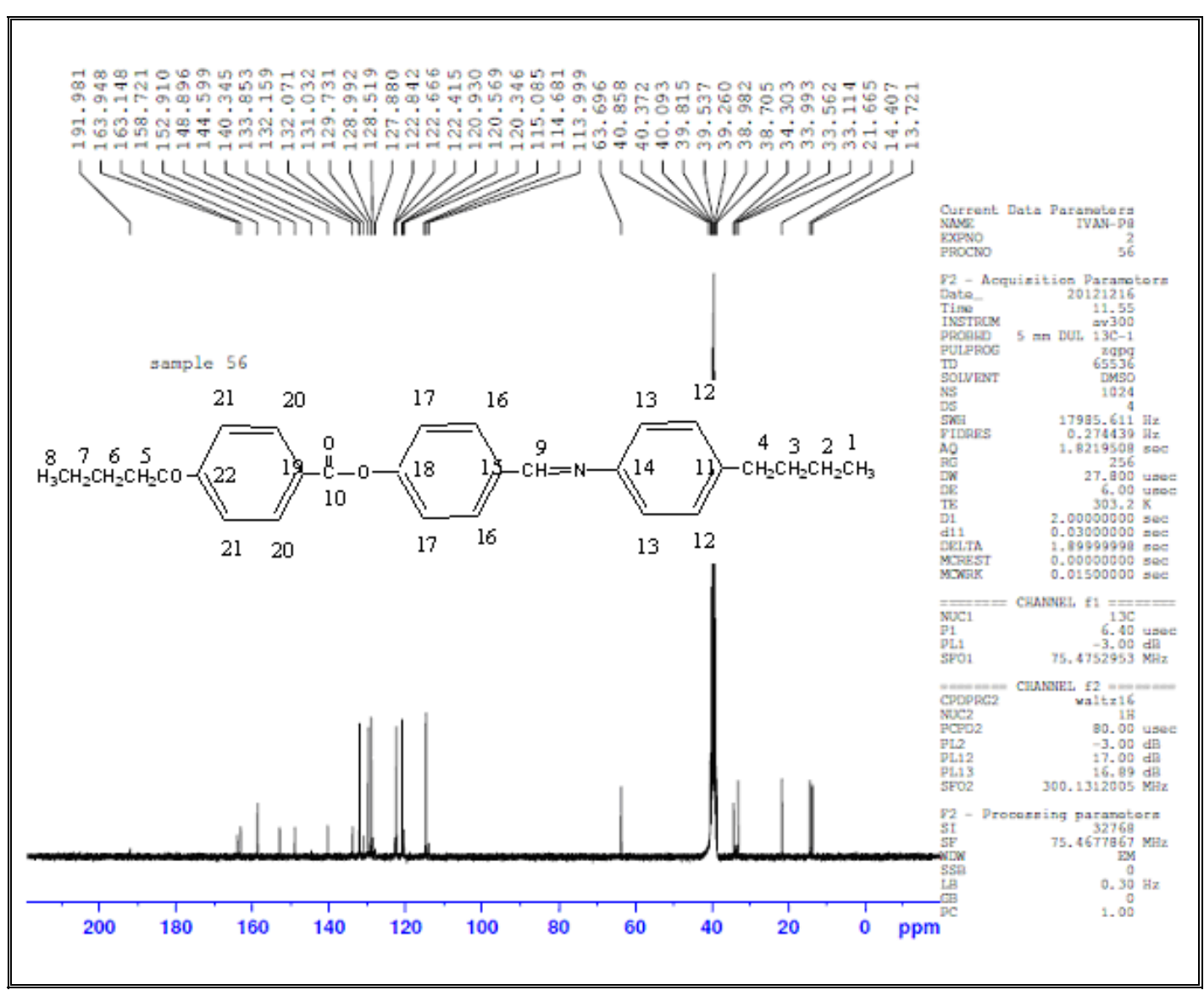

Fig.(4) ${ }^{13}$ CNMR spectrum for compound $4 d$. 
Table (2)

FTIR spectral data for synthesized compounds.

\begin{tabular}{|c|c|c|c|c|c|c|c|}
\hline $\begin{array}{l}\text { Comp } \\
\text { No. }\end{array}$ & $\begin{array}{l}\text { RO - } \\
\text { group }\end{array}$ & $\begin{array}{c}\text { v C-H Aro. } \\
\mathrm{cm}^{-1}\end{array}$ & $\begin{array}{c}\text { v C-H Aliph. } \\
\mathrm{cm}^{-1} \\
\end{array}$ & $\begin{array}{c}\mathrm{v} C=O \mathrm{~cm}^{-1} \\
\text { Ald. }\end{array}$ & $v C=N \mathrm{~cm}^{-1}$ & v $C=C \mathrm{~cm}^{-1}$ & $\begin{array}{c}\mathrm{vC}=\mathrm{O} \mathrm{cm}^{-1} \\
\text { Ester }\end{array}$ \\
\hline $3 a$ & $-\mathrm{OCH}_{3}$ & 3078.9 & $2904.5-2856.3$ & 1722 & - & 1560.9 & 1741 \\
\hline $3 d$ & $-\mathrm{OC}_{4} \mathrm{H}_{9}$ & 3080.1 & $2981.7-2829.4$ & 1738 & 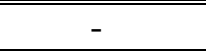 & 1534.1 & 1747 \\
\hline $3 h$ & $-\mathrm{OC}_{8} \mathrm{H}_{17}$ & 3064.4 & $2920.2-2854.4$ & 1724 & 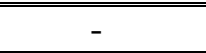 & 1602.7 & 1749 \\
\hline $4 a$ & $-\mathrm{OCH}_{3}$ & 3025.3 & $2953.8-2839.0$ & - & 1618 & 1572.9 & 1742 \\
\hline $4 b$ & $-\mathrm{OCC}_{2} \mathrm{H}_{5}$ & 3076.5 & $2974.0-2864.1$ & - & 1620 & 1551.8 & 1735 \\
\hline $4 c$ & $-\mathrm{OC}_{3} \mathrm{H}_{7}$ & 3035.0 & $2943.7-2863.1$ & 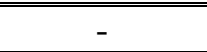 & 1623 & 1534.6 & 1747 \\
\hline $4 d$ & $-\mathrm{OC}_{4} \mathrm{H}_{9}$ & 3085.6 & $2959.4-2886.0$ & - & 1625 & 1583.2 & 1752 \\
\hline $4 e$ & $-\mathrm{OC}_{5} \mathrm{H}_{11}$ & 3077.1 & $2935.7-2848.7$ & - & 1621 & 1581.5 & 1744 \\
\hline $4 f$ & $-\mathrm{OC}_{6} \mathrm{H}_{13}$ & 3081.3 & $2968.1-2852.4$ & 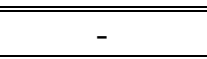 & 1628 & 1562.3 & 1738 \\
\hline $4 g$ & $-\mathrm{OCC}_{7} \mathrm{H}_{15}$ & 3046.9 & $2942.5-2876.2$ & 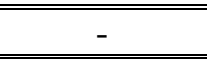 & 1622 & 1549.6 & 1743 \\
\hline $4 h$ & $-\mathrm{OC}_{8} \mathrm{H}_{17}$ & 3062.1 & $2984.3-2861.4$ & 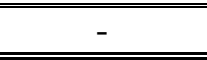 & 1626 & 1575.2 & 1744 \\
\hline
\end{tabular}

\section{Mesomorphic properties}

The synthesized compounds exhibited interesting thermotropic properties and its melting behavior was carefully monitored by POM during both heating and cooling scans. The results from the POM observation were verified by the DSC measurements. The transition temperatures and phase sequences are summarize in Table 3. Phase identification was based on the optical textures, and the magnitude of isotropization on enthalpies is consistent with the assignment of each mesophase type, using the classification systems reported by Sackmann and Demus (1966) and Gray and Goodby (1984) [18-19]. Under POM, nematic texture was observed (Fig.(5)). Out of the eight compounds, the first two members ( $\mathrm{C} 1$ and $\mathrm{C} 2$ ) did not possess mesomorphic properties. These molecules with short alkyloxy chains are too rigid, therefore have high melting points, thus impeding their liquid crystal properties [20]. Once the length of the terminal chain is increased, the molecule becomes more flexible, hence promoting a single mesophase in a particular compound. Therefore, the C3 C8 members exhibited nematic mesophase. All compounds, from $\mathrm{C} 3$ and $\mathrm{C} 8$ are enantiotropic liquid crystals because the stable mesophases were observed during both heating and cooling processes. From the graph, the lower member of the homologous series, C3, possessed the highest melting temperature $\left(\mathrm{Tm}=166^{\circ} \mathrm{C}\right)$.
The melting point decreased as the length of the chain increased to the $\mathrm{C} 8$ member $(\mathrm{Tm}=110 \mathrm{C})$. This resulted from the increase in the flexibility of the molecule owing to the longer alkyl chain. It is also common that the melting temperature increases from the medium chain member onwards following a decrease from the short to the medium chain members [21]. This ascending trend could have been attributed to the increase in the Van der Waals attractive forces between the molecules [22]. As the series ascends from the $\mathrm{C} 1$ to the $\mathrm{C} 2$ member, the $\mathrm{C}$-to- I transition temperatures attenuates consistently. The even members possessed high clearing temperatures compared to their odd member counterparts. Such attenuation of the melting temperatures has been observed in various homologous systems of liquid crystals [23]. While the C3 to $\mathrm{C} 6$ members exhibited an increase in their transition temperatures during the N-to-I transition, $\mathrm{C} 7$ and $\mathrm{C} 8$ exhibited smectic mesophase, the terminal intermolecular attractions play a role in determining the N-I transition temperatures, that is, the destruction of the nematic molecular order is determined by the fact that the terminal attractions become weaker, allowing partial interpenetration of the layers to occur more easily as the alkoxy chains grow longer, in turn depressing the S-to-I transition temperatures [24]. 
Table (3)

Melting points and type of transition for compounds $4 a-h$.

\begin{tabular}{|c|c|c|}
\hline Comp. No. & Melting point ${ }^{\circ} \mathrm{C}$ & Transition \\
\hline $4 a$ & $176-179$ & $\mathrm{C} \rightarrow \mathrm{I}$ \\
\hline $4 b$ & $168-170$ & $\mathrm{C} \rightarrow \mathrm{I}$ \\
\hline $4 \mathrm{c}$ & $154-166$ & $\mathrm{C} \rightarrow \mathrm{N}$ \\
\hline $4 \mathrm{~d}$ & $115-155$ & $\mathrm{C} \rightarrow \mathrm{N}$ \\
\hline $4 \mathrm{e}$ & $120-140$ & $\mathrm{C} \rightarrow \mathrm{N}$ \\
\hline $4 \mathrm{f}$ & $121-130$ & $\mathrm{C} \rightarrow \mathrm{N}$ \\
\hline $4 \mathrm{~g}$ & $117-125$ & $\overline{\mathrm{C}} \rightarrow \mathrm{Sm}$ \\
\hline $4 \mathrm{~h}$ & $1110-119$ & $\mathrm{C} \rightarrow \mathrm{Sm}$ \\
\hline
\end{tabular}

$C=$ Crystal $; S m=$ Smectic $; N=$ Nematic $;$ I = Isotropic liquid.

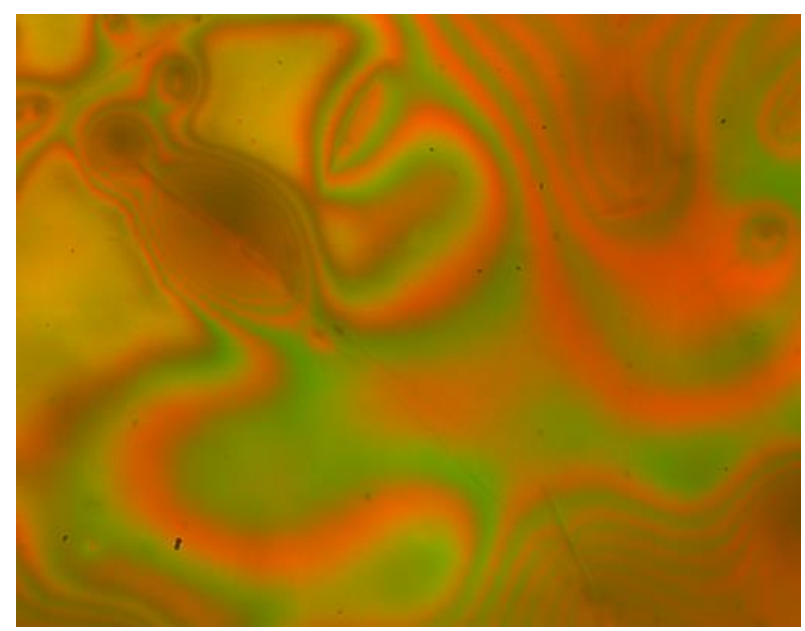

Fig.(5) Nematic texture of compound $4 d$.

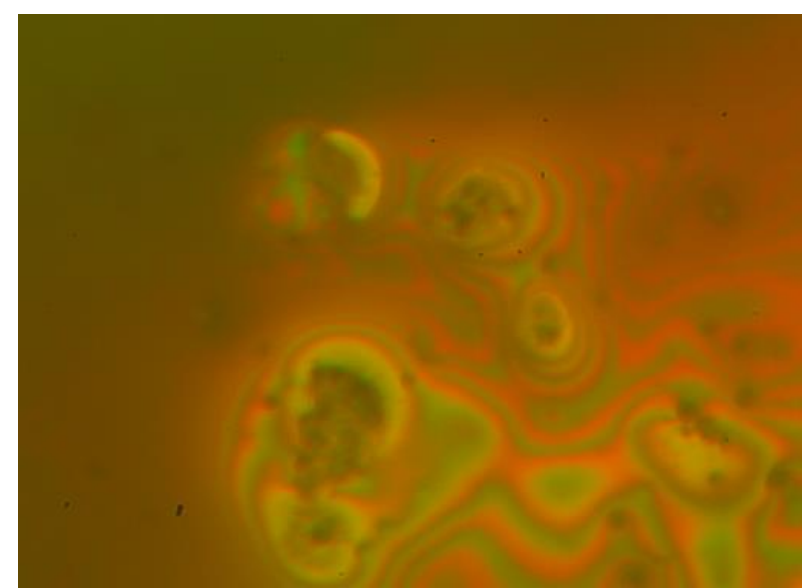

Fig.(6) Nematic texture of compound $4 f$.

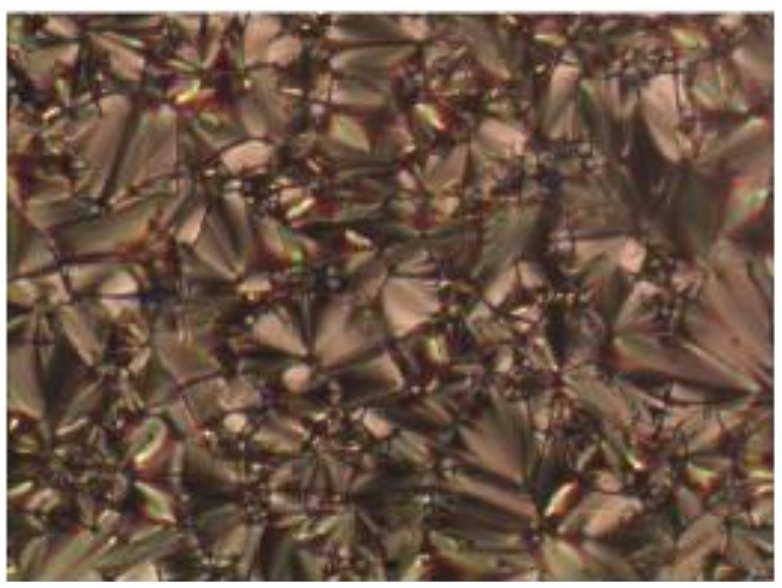

Fig.(7) Smectic texture of compound $4 \mathrm{~h}$.

\section{Acknowledgement}

The authors would like to thank chemistry department in al-Nahrain University and Ministry of Science and technology for the financial supports and research facilities.

\section{References}

[1] Petti L, Rippa M, Fiore A, Manna L, Mormile P, "Optically induced light modulation in an hybrid nanocomposite system of inorganic $\mathrm{CdSe} / \mathrm{CdS}$ nanorods and nematic liquid crystals", Opt. Mater., 32, pp.1011-1016, 2010.

[2] Hoang MH, Cho MJ, Kim KH, Lee TW, Jin JI, Choi DH, "Semiconducting 2,3,6,7,10,11- hexakis $\quad$ \{4-(5dodecylthiophen -2yl) phenyl] ethynyl triphenylene and its discotic liquid crystalline properties", Chem. Lett., 39, pp. 396-397, 2010.

[3] Yuksel F, Atilla D, Ahsen V, "Synthesis and characterization of liquid crystalline unsymmetrically substituted phthalocyanines". Poly hedron. 26, pp. 4551-4556, 2007.

[4] Zhang BY, Meng FB, Tian M., Xiao WQ, "Side-chain liquid-crystalline polysiloxanes containing ionic mesogens and cholesterol ester groups", React. Funct. Polym., 66, pp. 551-558, 2005.

[5] Singh S, Dunmur DA, "Liquid Crystals: Fundamentals", World Scientific Publishing Co. Pte. Ltd. London, 2002. 


\section{Science}

[6] Kelker H, Scheurle B, "A liquid crystalline (nematic) phase with a particularly low solidification point", Angew. Chem. Int. Edn., 8, pp. 884-885, 1969.

[7] Eran BE, Nesrullajev A, Canli NY, "Characterization and investigation of the mesogenic, thermo-morphological and thermotropic properties of new chiral (S)-5-octyloxy-2- [\{4-(2-methylbuthoxy) phenylimino (methyl) phenol liquid crystalline compound", Mat. Chem. Phys., 111, pp. 555-558, 2008.

[8] Ha ST, Ong LK, Ong ST, Yeap GY, Wong JPW, Koh TM, Lin HC, "Synthesis and mesomorphic properties of new Schiff base esters with different alkyl chains", Chin. Chem. Lett. 20, pp. 767-780, 2009.

[9] Prajapati AK, Varia CC, "Azomesogens with polar chloro, nitro and phenolic $-\mathrm{OH}$ substituents. Liq. Cryst"., 35, pp. 12711277, 2008.

[10] Yeap GY, Ha ST, Boey PL, Mahmood WAK, Ito MM, Youhei Y, "Synthesis and characterization of some new mesogenic Schiff base esters N-[4(4-n-hexadecanoyloxy benzoyloxy) benzylidene] -4- substitued anilines", Mol. Cryst. Liq. Cryst., 452, pp. 73-90, 2006.

[11] Yeap GY, Ha ST., Boey PL, Ito MM, Sanehisa S, Youhei Y, "Synthesis, physical and mesomorphic properties of schiff base esters containing ortho-, meta- and parasubstituents in benzylidene-4alkanoyloxyanilines. Liq. Cryst.”, 33, pp. 205-211, 2006.

[12] Collings PJ, Hird M, Introduction to Liquid Crystals Chemistry and Physics. Taylor \& Francis Ltd.London, 1998.

[13] Galewski Z, Coles HJ, "Liquid crystalline properties and phase situations in 4chlorobenzylidene-4'-alkylanilnes", J. Mol. Liq., 79, pp. 77-87, 1999.

[14] Galewski Z, "Liquid crystalline properties of 4-halogenobenzyline-4-alkoxyanilines", Mol. Cryst. Liq. Cryst., 249, pp. 43-49, 1994.

[15] Dave JS, Menon M, "Azomesogens with heterocyclic moiety", Bull. Mater. Sci. 23, pp.237-238, 2000.

[16] Chauhan M., Bhoi D., Machhar M., Solanki D. and Dhaval S., "Synthesis, characterization and mesomorphic properties of azoester mesogen: 4-n-alkoxy benzoic acid 4-[3-(benzylideneamino)phenylazo]-phenyl ester", Pharma Chemica, 2(4), pp.30-37, 2010.

[17] Yeap GY, Ha ST, Lim PL, Boey PL, Mahmood WAK, Ito MM, Sanehisa S, "Synthesis and mesomorphic properties of Schiff base esters ortho-hydroxy-paraalkyloxy- benzylidene-para-substituted anilines", Mol. Cryst. Liq. Cryst., 423, pp. 73-84, 2004.

[18] Sackmann H, Demus D, "The polymorphism of liquid crystals", Mol. Cryst. Liq. Cryst., 2, pp. 81-102, 1966.

[19] Gray GW \& Goodby JW, Smectic Liquid Crystals: Textures and Structures, Leonard Hill, 1984.

[20] Kumar S, "Liquid Crystals", Experimental Study of Physical Properties and Phase Transitions, Cambridge University Press, Cambridge, 2001.

[21] Kelker H, Hatz R, Handbook of Liquid Crystals. Verlag Chemie, Florida, 1980.

[22] Gray GW, Molecular structure and properties of liquid crystals. Academic Press, London, 1962.

[23] Prajapati AK, Bonde NL, "Mesogenic benzothiazole derivatives with a polar nitro substituent", Mol. Cryst. Liq. Cryst., 501, pp. 72-85, 2009.

[24] Solomons TWG, "Fundamentals of organic chemistry", John Wiley \& Sons, New York, 1994.

\section{الخلاصة}

تم دراسة سلاسل منماثلة جديدة لقواعد شف الحاوية على

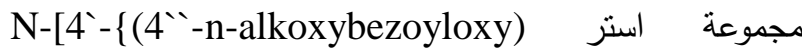
"benzylidene\} -4-butyl- aniline تعويض مجموعة الالكوكسي على الاستقطاب الجزيئي والذي تلئي

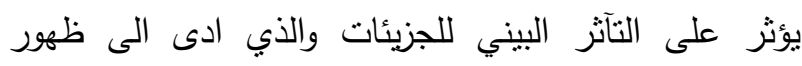
اطوار متعددة نيماتي وسمكتي. تم تشخيص الصفات البلورية

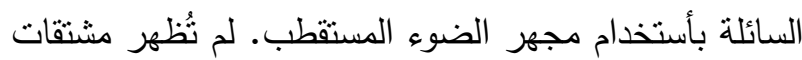
الميثوكسي والايثوكسي اي صفات بلورية سائلة، بينما اظهرت

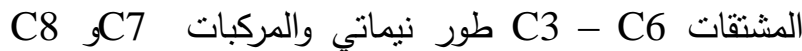
طور سمكتي. تم استخدام مطيافية الاشعة تحت الحمراء والرنين النووي المغناطيسي للبروتون والكاربون وطيف الكتلة وتحليل العناصر لتوضيح التركيب الجزيئي للمركبات المحضرة، في حين تم استخدام مجهر الضوء المستقطب 
لتعيين الصفات البلورية السائلة. لوحظ تأثير زيادة طول

مجموعة الالكيل على ظهور الصفات البلورية السائلة. 